\title{
Journal of Addiction Research and Therapies
}

Jackson DO, et al. J Addict Ther 2017: J113.

Research Article

DOI: $10.29011 /$ JATP-113/100013

\section{Substance Use Disorders Psychotropic Pharmacotherapy among Community Corrections Offenders-Correlates of Drug Abstinence and Diversion Discharge Status}

\author{
Dorothy O Jackson', Sylvie Mrug1, Foster Cook², William Beidleman ${ }^{3}$, \& Karen L. Cropsey \\ ${ }^{1}$ Department of Psychology, University of Alabama, Birmingham, USA \\ ${ }^{2}$ Department of Psychiatry and Behavioral Neurobiology, University of Alabama, Birmingham, USA \\ ${ }^{3}$ Birmingham Veterans Affairs Medical Center, USA
}

*Corresponding author: Dorothy O Jackson, Department of Psychology, University of Alabama, Birmingham, Tel: +205 960-2640; E-mail: Ocky_888@hotmail.com

Citation: Jackson DO, Mrug S, Cook F, Beidleman W, Cropsey KL (2017) Substance Use Disorders Psychotropic Pharmacotherapy among Community Corrections Offenders-Correlates of Drug Abstinence and Diversion Discharge Status. J Addict Ther 2017: J113. DOI: 10.29011/JATP-112/100013

Received Date: 01Febryaury, 2017; Accepted Date: 15 February,2017; Published Date: 21 February, 2017

\begin{abstract}
Offenders with Co-Occurring Disorders (COD) are at risk for poorer treatment outcomes in terms of substance use and recidivism. Substance abstinence and diversion program discharge status were compared using chi-square and ANOVA analyses among community corrections offenders $(\mathrm{N}=5,595)$ with substance use disorders who were taking psychotropic medications (SUPM), offenders with a Substance Use Disorder (SUD) only and offender who met neither criterion (controls).

Controls were more likely to have positive a positive discharge status and SUD only offenders were most likely to have negative dispositions. SUPM offenders were more likely to fail a urine drug screen at the middle and end of supervision than those with SUD only. This suggests various implications including access to care and the importance of mental health screenings among this population-as undiagnosed psychiatric problems likely contributed to observed differences.
\end{abstract}

Keywords: community corrections; co-occurring disorders; discharge status; diversion; drug abstinence; psychotropic medications

\section{Introduction}

In 2007, the Bureau of Justice Statistics (BJS) estimated that a total of over 7 million people in the United States were involved in some phase of the criminal justice system, including jail $(780,000)$, prison (1.5 million), probation (4.3 million), and parole $(820,000)$ [1]. Drug-related crimes result in a large percentage of these arrests and convictions [2,3] with drug offenders accounting for one fifth of the total growth of state prison populations between1990-2000 [4]. An even larger increase in the number of federal prison inmates was directly related to drug convictions with drug offenders accounting for $56 \%$ of the federal prison population in 2001 [4].
Within the community, the relationship between substance misuse and legal problems is equally as observable. Approximately two-thirds of patients in residential drug treatment centers, one-half of clients in outpatient drug treatment, and a quarter of methadone maintenance patients are currently awaiting criminal sentencing, serving community service or probation, or on parole [5]. There is evidence to suggest that drug use itself increases the likelihood for criminal behavior. More than half of violent crimes, $60-80 \%$ of child abuse/neglect cases, $70 \%$ of theft-related crime, and $75 \%$ of drug dealing, trafficking, and manufacturing charges involve drug use on the part of the perpetrator at the time of the offense $[6,7]$. Beyond the role of drugs in the perpetration of crime, persons convicted of drug charges present the greatest risk for parole/probation failure due to technical

violations like failing a urine drug screen or failing to meet with their parole officer $[8,9]$. Such evidence of poor outcomes 


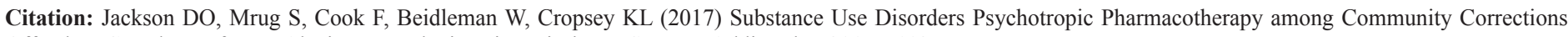
Offenders-Correlates of Drug Abstinence and Diversion Discharge Status. J Addict Ther 2017: J113.

suggests that the underlying addiction these individuals face cannot continue to be ignored.

Similarly, mental health problems are common among correctional populations. A 2005 report of the BJS estimated that more than half of all prison and jail inmates suffered from a mental health disorder, with the most commonly reported mental health symptoms being mania, major depression, and psychosis [10]. Problematic substance use is also more prevalent among inmates with a mental health diagnosis. A recent examination revealed substance use disorders (SUDs) in $76 \%$ of jail inmates, $74 \%$ of state prisoners, and $64 \%$ of federal prisoners with mental health diagnoses, which was significantly higher than rates found in inmates without a mental health diagnosis: $53 \%$ in jails, $56 \%$ in state prisons, and 49\% in federal prisons [10]. Thus, co-occurring disorders (COD), defined here as an Axis-I substance use disorder and another organic (non-substance induced) mental illness, are highly prevalent among criminal offenders. The BJS reports approximately three-quarters of jail and prison inmates with SUDs have a mental illness [10,11]. Latest estimates show that 1 in 10 males and 5 of every 10 females re-entering the community after incarceration have a diagnosis of COD [12].

Latest estimates show that 4.5 -5 million offenders are under supervised release each year $[13,14]$. This not only includes those released from prison on parole, but it also includes offenders that avoid serving prison time due to diversion programs. Despite the fact that the largest sector of the criminal justice system is supervised under community corrections, also known as non-institutional corrections, no estimates of COD rates among community corrections offenders or other offenders in the pre-sentencing phase are available.

COD offenders face multiple challenges to successful community reintegration. Mental illness reduces successful treatment completion rates and increases risk for relapse after treatment $[15,16]$. Despite their contact with the criminal justice system, which would seem like an ideal segue to intervention, many offenders with COD are not identified for psychiatric treatment. Studies have found that COD offenders often complete mandated interventions for their substance use problems without ever having their mental health disorders diagnosed [17]. It has been suggested that accurate assessment of COD is impeded by the residual effects of substance use (e.g. withdrawal symptoms) that may mimic more obscure symptoms of the organic mental illness [18]. In terms of recidivism rates, COD drug offenders are more likely to be reincarcerated during their first year of parole release than drug offenders without a mental health condition $[19,20]$. When one takes into account that following an individual's first incarceration, he or she is likely to be 1) unemployable due to a prior conviction; 2) un- insured due to their lack of employment, and therefore 3) not able to seek treatment for their addiction or mental health problems, a vicious cycle of incarceration, release, and recidivism is likely to continue without more emphasis on treatment in the U.S. criminal justice system.

The purpose of this study was to examine persons with substance use disorders who were maintained on psychotropic medications (SUPM) for a range of mental disorders. These offenders represented COD status within a sample of community corrections offenders. This study aimed to compare drug abstinence as measured by urine drug screens and diversion program dispositions across three groups: SUPM offenders, those with Substance Use Disorders only (SUD only), and those that were neither diagnosed with substance abuse/dependence nor endorsed mental health treatment.

\section{Method}

\section{Setting}

Treatment Alternatives for Safer Communities (TASC) was developed as a case management model to link offenders to community substance abuse treatment services [21]. TASC operates under the assumptions that drug addiction produces a cycle of crime, incarceration, release, and relapse among offenders, and that this cycle provides frequent opportunities for meaningful treatment interventions [22]. The basic functions of a TASC program include: 1) identifying appropriate candidates, 2) assessing treatment needs, 3) referring clients to treatment and other services, and 4) providing client-centered case management [21]. A review of seven program TASC sites across the country found favorable outcomes, such as reductions in drug use, crime, and HIV risk behavior over the typical criminal justice system trajectory [23].

The University of Alabama at Birmingham's (UAB) TASC program operates under the Jefferson County Drug Court system. TASC offers a number of referral options to address clients' social needs, including addiction

treatment, parenting/DHR needs, vocational training, housing needs, and mental health referrals. Offenders requiring substance use treatment may be referred for inpatient treatment or referred to the UAB Beacon Addiction Program, an outpatient drug treatment program that is housed within the same facility as the TASC offices.

\section{Procedures}

All offenders charged with felony offenses in Jefferson County are required to report to TASC for their initial assessment within 48 hours of making bond. At their initial visit, offenders are administered a urine drug screen and assigned a case manager to 


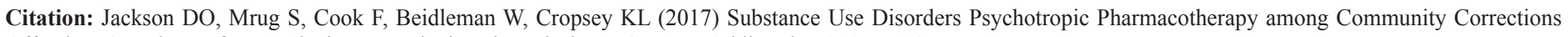
Offenders-Correlates of Drug Abstinence and Diversion Discharge Status. J Addict Ther 2017: J113.

administer an intake interview once the drug test results are available (within an hour). Incoming TASC clients were asked about their socio-demographic background, criminal charges, mental health histories, and medical histories, and are screened for substance abuse/dependence. Unique case identifier is assigned to each client upon their first contact (first charge that introduces them to the program) with TASC. Clients retain this identifier for all subsequent referrals. Therefore, only the first referring charge was considered for this analysis. Approval from UAB's Institutional Review Board (IRB) was granted to examine de-identified data that had been collected by TASC for the purposes of treatment planning and case management. The IRB approved an exemption from documented informed consent of participants.

\section{Participants}

Between 2002 and 2007, a total of 24,365 men and women were required to report to TASC. There they were administered intake interviews that asked about their socio-demographic background, health histories, legal history, and substance use. Of the total sample, approximately $7.5 \%(\mathrm{n}=1,845)$ were identified as SUPM. SUPM participants were defined by having at least one Axis I substance use disorder and taking psychotropic medications at the time of the interview. Of the remaining cases, a sub-sample of those that met criteria for substance abuse/dependence only $(\mathrm{N}=1,876)$ was randomly selected for comparison. In addition, a random sample of 1,874 cases was selected from participants who did not meet criteria for substance abuse/dependence and who did not endorse taking any psychotropic medications, but were assigned to case management by TASC for jail diversion. These three groups yielded a total sample size of 5,595. A series of univariate analyses revealed no significant difference in demographics (age, race, gender, and level of education) between the subsets of substance use only clients and controls that were randomly selected for analysis versus those that were not selected.

The mean age for participants was 32.6 years with an average of 1.3 children. The sample was predominately male $(70.9 \%)$ and Black (53.4\%). In terms of education, 37.4\% percent of participants had less than a high school education, $33.3 \%$ had a high school diploma or GED, and $28.6 \%$ had more than a high school education. Over half $(54.7 \%)$ of the sample had never been married, slightly more than a quarter $(26.1 \%)$ were divorced or separated, and less than a fifth (19.1\%) were married at the time of the study. Nearly half of the sample was unemployed $(49.2 \%)$ with more than half being without medical insurance $(57.6 \%)$. A large proportion of participants in this sample (37.9\%) fell within the category of extreme poverty, earning less than $\$ 6,000$ per year. Approximately one fifth (19.9\%) of the participants were on probation at the time of the intake interview. Less than two percent
$(1.6 \%)$ were on parole. As expected in TASC populations, the majority $(87.5 \%)$ of participants was charged with a felony offense and was being monitored in the community prior to adjudication.

The primary charges among the participants were unlawful possession of a controlled substance $(32.7 \%)$, possession of marijuana (12.1\%), and theft of property (10.3\%). The most prevalent substance abuse/dependence diagnoses were for marijuana $(40.6 \%)$, cocaine $(32.2 \%)$, alcohol $(25.4 \%)$ and opiates $(19.3 \%)$. Substance use diagnoses were not mutually exclusive and that an offender could meet criteria for more than one drug. More than two thirds of clients failed at least one urine drug screen at some point during their treatment $(67.2 \%)$.

\section{Measures}

\section{Intake Assessment}

The TASC intake interview is a semi-structured interview where the case manager directly inputs the client's responses into a computer database. The interview typically takes an hour and half to two hours to complete and covers socio-demographic data, medical history, psychiatric history, current prescribed medications, extensive

information about the current charge, and past criminal history. It also includes a checklist of DSM-IV substance abuse and dependence criteria. In 2008, the data collected between 20022007 was extracted from the TASC database and transferred to SPSS for analyses.

\section{Demographics}

Clients' age, gender, and race were entered at the beginning of the intake interview. Clients were also asked about their marital status and education. Race was divided into two categories: White and Non-White. Education was coded into three groups: less than a high-school diploma or equivalent, high school diploma or equivalent, and any post-secondary schooling. Marital status was coded into three levels: single/never married, married, and divorced/widowed. Each client's employment status and household income was noted at the time of their intake assessment. Finally, each client was asked about their current access to medical health insurance. Responses were categorized as uninsured, government-aided coverage (e.g., Medicaid, Veteran's Benefits), or private insurance.

\section{Grouping Variables}

During the intake interview, clients were asked if they had ever received any treatment for a mental health problem (counseling, medication, inpatient hospitalization). Clients were also queried about their use of prescription medications for both general health conditions and psychiatric/emotional disturbances. Current 


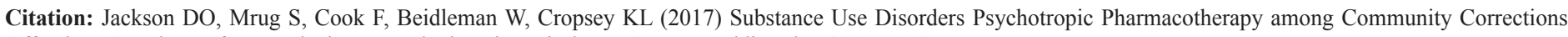
Offenders-Correlates of Drug Abstinence and Diversion Discharge Status. J Addict Ther 2017: J113.

prescriptions were confirmed by the client's case manager in order to document each client's use of prescription medication. Clients were screened for problem substance use behaviors using a DSMIV defined checklist in order to identify substance abuse or dependence for the following illicit substances: alcohol, marijuana, cocaine, opiates, sedative hypnotics, and amphetamines.

Clients who endorsed being treated for mental health or emotional problems, endorsed taking a psychotropic medication, and met criteria for substance abuse or dependence for at least one illicit drug were categorized as SUPM. Those who met criteria for substance abuse or dependence and who denied ever receiving treatment for mental or emotional problems, including psychotropic pharmacotherapy, were categorized as SUD only. Finally, those that denied taking psychotropic medications, had never received any other mental health services, and did not meet criteria for substance abuse or dependence constituted the control group. As stated earlier, randomly selected subsamples of SUD only and controls were selected for comparison with the SUPM group.

\section{Diversion Program Variables}

The first diversion program variable for this study was the offender's discharge status. Each client was given a status disposition at their last TASC visit which was entered into the TASC database. This variable provided an indicator of compliance to the diversion program. There were a total of 24 potential status levels, which were categorized as positive (successful completion), neutral (case ended due to circumstances unrelated to the offender's compliance to TASC requirements), or negative (non-successful completion). Categories of status outcomes are shown in Table 1. The criteria for program success or failure were not fixed. The number of allowable infractions (e.g., failed urine drug tests or missed meetings) varied by individual cases and was often influenced by a number of mitigating factors. This determination may have been made by the judge presiding over the case, but was often left to the recommendation of the offender's TASC counselor.

\begin{tabular}{|c|c|c|}
\hline Negative & Neutral & Positive \\
\hline Failed-New Case & Death & Success \\
\hline $\begin{array}{l}\text { Failed-Non Com- } \\
\text { pliant }\end{array}$ & Denied & Success- Has Balance \\
\hline FTA in Court & Failed to Return & $\begin{array}{l}\text { Success w/o Disposi- } \\
\text { tion }\end{array}$ \\
\hline $\begin{array}{c}\text { Incarcerated Non } \\
\text { Compliant }\end{array}$ & Interrupted & $\begin{array}{c}\text { Transfer to Drug } \\
\text { Court }\end{array}$ \\
\hline $\begin{array}{c}\text { Set Aside-Never } \\
\text { Reported }\end{array}$ & Neutral & Transfer to Probation \\
\hline $\begin{array}{l}\text { Set Aside-Non } \\
\text { Compliant }\end{array}$ & Neutral- Incarcerated & \\
\hline
\end{tabular}

\begin{tabular}{|c|c|l|}
\hline & Neutral- Medical & \\
\hline & $\begin{array}{c}\text { Noll Prossed- System } \\
\text { Drop }\end{array}$ & \\
\hline & Non-Volunteer & \\
\hline & Pending & \\
\hline & Rejected & \\
\hline & Status NA & \\
\hline $\mathrm{N}=2,192(36 \%)$ & Withdrew & \\
\hline
\end{tabular}

Table 1: Categorical TASC Status Dispositions

The second diversion program variable was substance abstinence as measured with urine drug screens. All offenders referred to TASC who met abuse/dependence criteria or were referred for drug-related charges, child abuse/neglect, or domestic violence were flagged to provide random urine drug screens on varied schedules. In order to address the varying numbers of urine drug tests completed by each participant, each participant's record was divided into 3 time-points: entry, mid-supervision, and end of supervision and the proportion of positive urine drug screens provided during each time interval was calculated. These percent positives were used to classify participants into several groups. The first indicator distinguished those who had ever failed a urine drug screen while under TASC supervision (1) versus those who had not (0). Then, three additional dichotomous variables were computed to indicate whether a participant ever failed a urine drug screen at the following time-points: beginning, middle, and end of their TASC supervision (all coded 1 for failing and 0 for not failing during that time period).

\section{Data Analysis}

A series of chi-square and ANOVA analyses was used to compare demographics between SUPMs, SUD only, and those with neither diagnosis. Two key demographic variables, race and gender, were combined to form a single group with four categories, White males, White females, Non-White males, and NonWhite females, in order to account for possible race and gender interactions. Chi-square tests were also used to compare status outcomes (positive, neutral, or negative) among SUPMs, SUD only offenders, and controls. Finally, SUPM and SUD only offenders were compared using chi-square tests on whether they had failed a urine drug screen during the entire course of TASC supervision and during the 3 time intervals - beginning, middle, and end of supervision. Because controls did not meet substance abuse/ dependence criteria at intake and thus were not subject to urine drug screens, they were omitted from analysis of these variables. Tukey's post-hoc analysis for ANOVAs and follow-up chi-square tests with Bonferroni correction were used to identify significant 


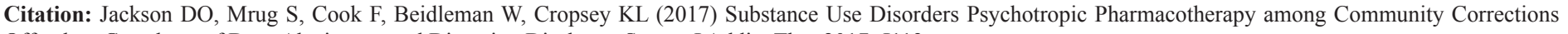
Offenders-Correlates of Drug Abstinence and Diversion Discharge Status. J Addict Ther 2017: J113.

group differences.

\section{Results}

\section{Demographics}

Group means and proportions for measured demographics and omnibus test statistics are presented in Table 2. Mean ages for the groups varied significantly, with SUPM offenders being older than SUD only and controls. Significant differences were also found in terms of race and gender, education, marital status, employment status, income, and medical coverage. In comparison to SUD only and controls, respectively, SUPM offenders were more likely to be White males $\left[\chi^{2}(1)=42.67, \mathrm{p}<.001 ; \chi^{2}(1)=113.83\right.$, $\mathrm{p}<.001]$ or White females $\left[\chi^{2}(1)=259.87, \mathrm{p}<.001 ; \chi^{2}(1)=\right.$ $340.11, \mathrm{p}<.001]$. SUPM offenders were more likely to report some post-secondary education than SUD only offenders $[\chi 2(1)=15.98$, $\mathrm{p}<.001]$ and controls $[\chi 2(1)=19.36, \mathrm{p}<.001]$. SUPM offenders were more likely to be divorced than both SUD only offenders $[\chi 2(1)=100.01, \mathrm{p}<.001]$ and controls $[\chi 2(1)=144.20, \mathrm{p}<.001]$. However, SUPM offenders were less likely to be unemployed than both SUD only offenders $\left[\chi^{2}(1)=160.65, \mathrm{p}<.001\right]$ and controls $[\chi 2(1)=330.20, p<.001]$. SUPM offenders were nearly identical to SUD only offenders in proportions earning less than $\$ 6000$ / year gross income, while controls were significantly less likely to fall in the lowest income bracket than SUPM $[\chi 2(1)=47.55, \mathrm{p}<$ $.001]$ and SUD only $[\chi 2(1)=61.12, p<.001]$. Controls were more likely to have private insurance than both SUPM $[\chi 2(1)=42.35$, $p<.001]$ and SUD only offenders $[\chi 2(1)=113.04, p<.001]$, with SUPM offenders being more likely to have government-facilitated health coverage than SUD only $[\chi 2(1)=218.29, \mathrm{p}<.001]$ and control offenders $[\chi 2(1)=164.31, \mathrm{p}<.001]$. SUD only offenders were more likely to have no medical insurance than SUPM $[\chi 2$ (1) $=39.26, \mathrm{p}<.001]$ and controls $[\chi 2(1)=98.58, \mathrm{p}<.001]$.

\begin{tabular}{|c|c|c|c|c|c|}
\hline Variables & $\begin{array}{c}\text { Co-occurring } \\
\text { SUPM (N=1,845) } \\
\text { N (\%) }\end{array}$ & $\begin{array}{c}\text { Substance use } \\
\text { only(N=1,876) } \\
\text { N (\%) }\end{array}$ & $\begin{array}{c}\text { Control } \\
(\mathrm{N}=1,874) \\
\mathrm{N}(\%)\end{array}$ & Test Statistics & p-value \\
\hline $\begin{array}{l}\text { Age in years, } \\
\text { mean (SD) }\end{array}$ & $34.7(10.3) \mathrm{a}$ & $30.6(10.1) \mathrm{b}$ & $31.0(11.0) \mathrm{b}$ & $F(2,5573)=85.86$ & $<.001$ \\
\hline Race by Gender & & & & $\chi 2(6)=854.49$ & $<.001$ \\
\hline White Male & $684(37.1) \mathrm{a}$ & $508(27.1) \mathrm{b}$ & $397(21.2) \mathrm{c}$ & & \\
\hline White Female & $591(32.0) \mathrm{a}$ & $196(10.5) \mathrm{b}$ & $148(7.9) \mathrm{b}$ & & \\
\hline Non-White Male & $385(20.9) \mathrm{a}$ & $1004(53.5) \mathrm{b}$ & $991(52.9) \mathrm{b}$ & & \\
\hline Non-White Female & $184(10.0) \mathrm{a}$ & $167(8.9) \mathrm{a}$ & $338(18.0) \mathrm{b}$ & & \\
\hline Unemployed & $1218(66.6) \mathrm{a}$ & $858(45.9) b$ & $678(36.6) \mathrm{c}$ & $\chi^{2}(2)=354.61$ & $<.001$ \\
\hline \multicolumn{4}{|c|}{ Education } & $\chi^{2}(4)=125.90$ & $<.001$ \\
\hline$<$ High school & $617(33.6) \mathrm{a}$ & $855(45.8) \mathrm{b}$ & $623(33.6) \mathrm{a}$ & & \\
\hline $\begin{array}{l}\text { High school or } \\
\text { GED }\end{array}$ & $564(30.7) \mathrm{a}$ & $610(32.7) \mathrm{a}$ & $689(37.2) \mathrm{b}$ & & \\
\hline College or higher & $656(35.7) \mathrm{a}$ & $402(21.5) b$ & $540(29.2) \mathrm{c}$ & & \\
\hline \multicolumn{4}{|c|}{ Marital status } & $\chi 2(4)=226.44$ & $<.001$ \\
\hline Never married & 779 (42.3)a & $1168(62.3) \mathrm{b}$ & $1116(59.6) \mathrm{b}$ & & \\
\hline Married & $378(20.5) \mathrm{a}$ & $294(15.7) b$ & $394(21.0) \mathrm{a}$ & & \\
\hline Divorced/widowed & $683(37.1) \mathrm{a}$ & $414(22.1) b$ & $362(19.3) \mathrm{b}$ & & \\
\hline $\begin{array}{l}\text { Gross Yearly } \\
\text { Income }\end{array}$ & & & & $\chi 2(8)=112.59$ & $<.001$ \\
\hline Less than $\$ 6,000$ & 757 (41.0)a & $797(42.5) \mathrm{a}$ & $566(30.2) \mathrm{b}$ & & \\
\hline$\$ 6,000-\$ 10,999$ & $280(15.2) \mathrm{a}$ & $226(12.0) \mathrm{a}$ & $171(9.1) \mathrm{a}$ & & \\
\hline$\$ 11,000-\$ 20,999$ & 214 (11.6)a & $280(14.9) b$ & $282(15.0) \mathrm{b}$ & & \\
\hline$\$ 21,000-\$ 29,999$ & $102(5.5) \mathrm{a}$ & $131(7.0) \mathrm{a}$ & $181(9.7) b$ & & \\
\hline
\end{tabular}




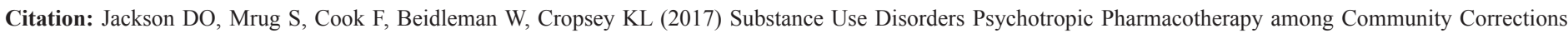
Offenders-Correlates of Drug Abstinence and Diversion Discharge Status. J Addict Ther 2017: J113.

\begin{tabular}{|c|c|c|c|c|c|c|}
\hline$\$ 30,000$ or more & $146(7.9) \mathrm{a}$ & $135(7.2) \mathrm{a}$ & $200(10.7) \mathrm{b}$ & & \\
\hline Medical Insurance & & & & \multicolumn{2}{|c|}{$\chi^{2}(2)=345.61$} & \\
\hline Private & $464(25.6) \mathrm{a}$ & $315(17.1) \mathrm{b}$ & $573(33.1) \mathrm{c}$ & & \\
\hline Medicaid or VA & $522(28.8) \mathrm{a}$ & $176(9.5) \mathrm{b}$ & $216(11.8) \mathrm{b}$ & & \\
\hline None & $828(45.6) \mathrm{a}$ & $1355(73.4) \mathrm{b}$ & $1041(56.9) \mathrm{c}$ & & & \\
\hline
\end{tabular}

a,b,c Different superscripts indicate significant group differences at Bonferroni corrected alpha level of $\mathrm{p}<.0125$ or less

Table 2: Group Demographics

\section{Discharge Status}

Group comparisons across the three discharge status classes are depicted in (Figure1). Significant group differences were identified among all comparisons. Follow-up analyses (using Bonferroni correction with adjusted $\mathrm{p}<.006$ ) showed that SUD only offenders were most likely to have a negative status at TASC discharge in comparison to SUPM offenders $[\chi 2(1)=35.01, p<.001]$ and controls $[\chi 2(1)=254.43, p<.001]$. SUPM offenders were more likely than controls to have a negative status upon their discharge from TASC $[\chi 2(1)=102.56, \mathrm{p}<.001]$. On the other hand, controls were more likely to have a neutral status than both SUPM [ $\chi 2(1)=$ $73.80, p<.001]$ and SUD only offenders $[\chi 2(1)=166.26, p<.001]$ who did not significantly differ in terms of neutral status dispositions. Finally, controls were also more likely to have positive discharge status in comparison to SUD only $[\chi 2(1)=13.72, p<.001]$ and SUPM offenders $[\chi 2(1)=8.17, p=.005]$, with no differences observed between these two groups $[\chi 2(1)=0.69, p=.41]$.

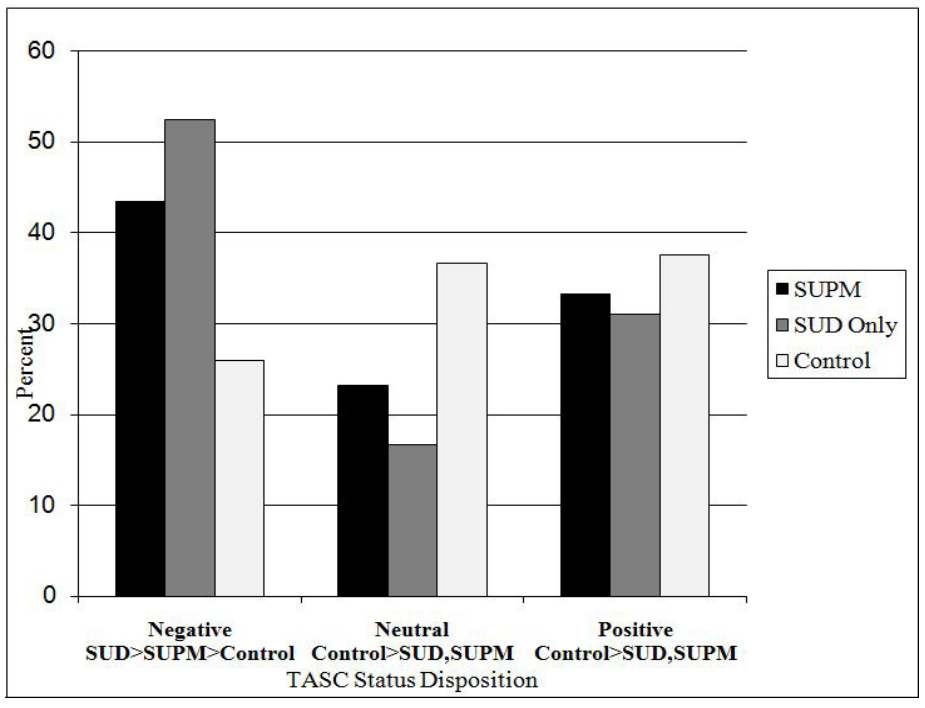

Figure 1: TASC Status Dispositions by Group

(Figure 2) displays group differences on positive urine drug screens throughout TASC supervision. No significant difference was foundbetween SUPM offenders and SUD only offenders in terms of whether they failed a urine drug screen at any point during their TASC supervision. However, when the duration of supervision was divided into three time periods, differences were found between the groups at the middle and end stages of treatment. SUPM offenders were more likely to fail a urine drug screen at both the middle [ $49.9 \%$ to $44.2 \% ; \chi 2(1)=12.26, \mathrm{p}<.001]$ and at the end of TASC supervision [50.2\% to $\left.46.4 \% ; \chi^{2}(1)=5.42, \mathrm{p}=.022\right]$ than SUD only offenders.

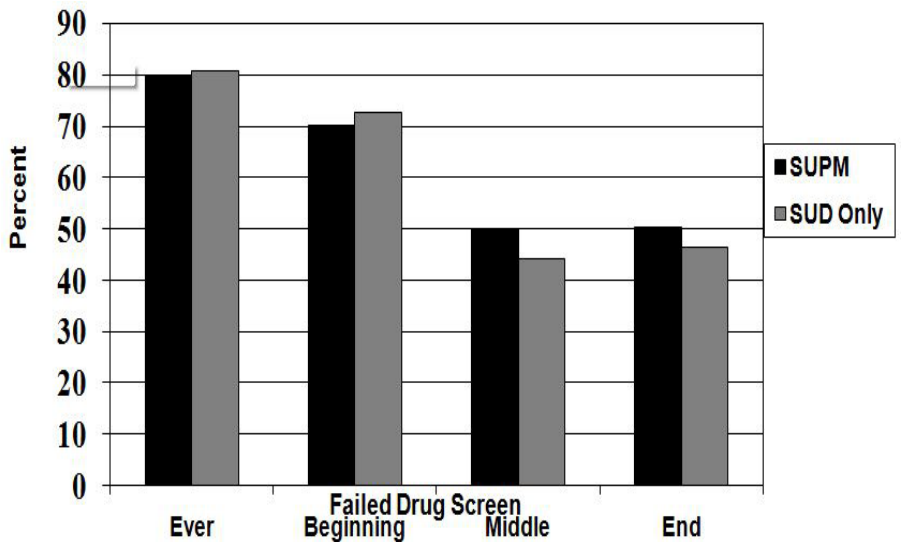

Figure 2: Urine Drug Screen Failures across TASC Supervision $* \mathrm{p}<.05 ; * * * \mathrm{p}<.001$

\section{Discussion}

This study is the first to examine offenders with comorbid substance use problems and mental health issues in community corrections settings, in contrast to the majority of research on COD offenders which has been conducted in institutional settings. Although we have not been able to assign formal psychiatric diagnoses to participants in the current study, it is likely that our sample included individuals with less severe psychiatric problems than typically examined in the literature, which has been largely restricted to serious mental illnesses, such as schizophrenia and bipolar disorders. It is possible that this study adds to the existing literature in that those with less severe psychiatric presentationsfor example, taking a psychotropic (e.g., anxiolytic or antidepressant), but not psychotic or otherwise functionally impaired-were likely included in this sample. 


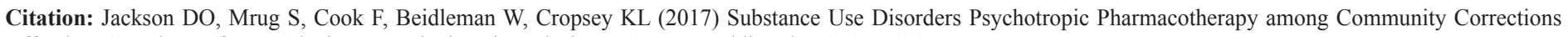
Offenders-Correlates of Drug Abstinence and Diversion Discharge Status. J Addict Ther 2017: J113.

Previous studies have indicated that rates of mental illness and substance misuse are higher among younger criminal justice offenders and among women (James \& Glaze, 2006). While the age difference was not replicated in the current study (SUPM were older than SUD only and controls), the current investigation found that White females and White males were more likely to belong in the SUPM group than SUD only or controls -a result that was generally consistent with the existing literature on mental illness and substance abuse/dependence in correctional populations. The literature has indicated a consistent racial difference in support of this finding, with White offenders being more likely to report a history of mental illness than non-Whites [8].

The fact that TASC offenders with SUD only fared significantly worse than both SUPM and control groups in terms of program outcomes appears at first glance to be discordant with prior research. In particular, a number of studies have suggested that COD offenders are less likely to enter and successfully complete treatment and are at greater risk for criminal recidivism and relapse $[24,25]$ However, because the group of individuals selected to represent COD status were substance users maintained on psychotropic medications (SUPM), a number of explanations for this outcome finding are plausible. Lower access to medical health insurance thus may have served as a major contributing factor to disparities in successful treatment outcomes. SUPM offenders were more likely to have medical insurance and presumably greater access to care; thus, they may have benefited from pharmacotherapy and increased contact with mental health providers than SUD only offenders. A possible confound and an explanation of the findings is that some individuals in the SUD only group suffered from mental illness that had gone undiagnosed and untreated due to lack of access to screening and referral sources. Perhaps these individuals did not experience symptoms that would be severe enough to warrant emergency interventions, and thus were overlooked. Interestingly, the SUPM and SUD offenders appeared

similarly economically deprived (i.e., they did not differ in gross year income), but SUPM offenders were more likely than SUD only offenders to have government subsidized health coverage, perhaps because they experienced more severe psychiatric problems that would qualify them for such coverage. Alternatively, the increased access to medical care among SUPM offenders may have been unrelated to the severity of their psychiatric problems, but may have still provided the opportunity for mental health screening, diagnosis, and treatment that was not available to the uninsured SUD only offenders.

One implication of the outcomes finding is that there is a need to broaden the net of screening and catchment within the correctional system as a whole, but particularly in the community corrections sector where low-cost treatment is often less acces- sible than in institutional settings. Expanding screening services in community corrections would likely help those "stuck in the middle"-economically deprived, yet not so severely impaired that they have made prior contact with emergency mental health providers and qualified for subsidized health insurance.

Considering the high demand for mental health services in correctional populations, it is likely that the current study underestimated the true extent of the problem of substance use and mental illness. Those identified to receive treatment are often experiencing more persistent and severe psychopathology [26]. Thus, offenders suffering from less severe disorders, such as dysthymia or anxiety, may be less likely to receive services due to higher demand of more critical cases and limited resources. Therefore, future studies should examine specific mental health symptoms and disorders present in community corrections populations in relation to services received to determine unmet mental health care needs in these settings. Other research should examine whether the full scope of presenting mental health problems can be adequately addressed at the supervision site or referred for community services, such as psychiatry consultations and intensive psychotherapy.

Several study limitations warrant discussion. The most important limitation was the lack of diagnostic information about mental health symptoms in the existing dataset. Consequently, we could define mental health problems only by current active treatment with psychotropic medication and a report of having used mental health services. As this data was not originally corrected for the purposes of this study, opportunity to document the diagnoses or condition for which the agent was prescribed was missed. Given these limitations, it is possible that some of the individuals who our defined SUPM criteria would not be diagnosed with a psychiatric disorder. Similarly, it is possible that the SUD only or control groups included offenders with psychiatric diagnoses that had not been diagnosed and/or treated. Therefore, the ability to generalize these findings to larger COD offender samples is limited. In order to more precisely identify COD in this special population, a diagnostic checklist for mental health symptoms should be added to intake interviews and administered in the same manner as the substance abuse and dependence criteria. Further, the requirements for successful program completion were largely defined by the offender's case manager, judge, and the findings of the intake assessment. It is important to note that SUD only and SUPM offenders were likely required to engage in more components of treatment than the controls. The secondary analysis approach employed was another limitation to this study. The data available included the detailed intake assessment, urine positives, and final discharge status. Future analyses could benefit from treatment process data to examine issues of adherence and engagement throughout supervision. Additionally, the cross-sectional design of 


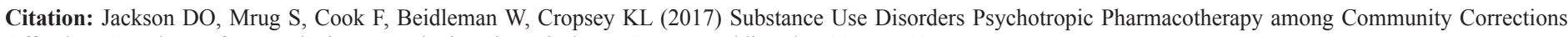
Offenders-Correlates of Drug Abstinence and Diversion Discharge Status. J Addict Ther 2017: J113.

the study limits inferences regarding the directionality of the obtained relationships.

In summary, the present study was one of the first to examine co-occurring substance use problems and active psychotropic therapy among offenders maintained under community corrections supervision. This study compared treatment outcomes between offenders with both documented substance use and psychiatric problems, those diagnosed with only substance use issues, and those with neither presentation and found that the SUD only were most likely to have negative outcomes, followed by SUPM offenders. Those with meeting neither, criteria for a SUD nor taking psychotropics were most likely to successfully complete TASC. Future studies should replicate these findings using direct assessments of psychiatric symptoms and diagnoses in community correction settings. Additionally, it would be valuable to evaluate treatment outcomes among groups defined by specific substance use and psychiatric diagnoses.

\section{References}

1. West HC, Sabol WJ (2008) Prisoners in 2007 (Publication No. NCJ224280). Department of Justice, Bureau of Justice Statistics. Washington, D.C. U.S.

2. Tyuse SW, Linhorst DM (2005) Drug courts and mental health courts: implications for social work. Health Soc Work 30: 233-240.

3. Speck PM, Connor PD, Hartig MT, Cunningham PD, Fleming B (2008) Vulnerable populations: Drug Court program clients. Nurs Clin North Am 43: 477-489.

4. Office of National Drug Control Policy. (2003)

5. Craddock G, Rounds-Bryant JL, Flynn PM, Hubbard RL (1997) Characteristics and pretreatment behaviors of clients entering drug abuse treatment: 1969-1993. The American Journal of Drug and Alcohol Abuse 23: 43-59.

6. Marlowe DB (2003) Integrating substance abuse treatment and criminal justice supervision. Sci Pract Perspect 2: 4-14.

7. Department of Justice, National Institute of Justice (1999) Annual report on drug use among adult and juvenile arrestees. Washington, D.C. U.S

8. Langan PA, Levin DJ (2002) Recidivism of prisoners released in 1994. (Publication No. NCJ-193427). Department of Justice, Bureau of Justice Statistics. Washington, U.S.

9. Lipton D S (1995) The effectiveness of treatment for drug abusers under criminal justice supervision. National Institute of Justice. Washington, U.S.

10. James DJ, Glaze LE (2006) Mental health problems of prison and jail inmates. (Publication No. NCJ213600). Department of Justice, Office of Justice Programs, National Institute of Justice. Washington, U.S.

11. Taxman FS, Cropsey KL, Melnick G, Perdoni MA (2008) COD services in community correctional settings: An examination of organizational factors that affect service delivery. Behav Sci Law 26: 435-455.
12. Mallik-Kane K, Visher CA (2008) Health and prisoner reentry: How physical, mental, and substance abuse conditions shape the process of reintegration. The Urban Institute.

13. Glaze LE, Bonczar TP (2008) Probation and parole in the United States, 2007 Statistical Tables. Department of Justice, Bureau of Justice Statistics, Office of Justice Programs, U.S

14. Taxman FS, Perdoni ML, Harrison LD (2007) Drug treatment services for adult offenders: The state of the state. J Subst Abuse Treat 32: 239-254.

15. Bradizza CM, Stasiewicz PR, Paas ND (2006) Relapse to alcohol and drug use among individuals diagnosed with co-occurring mental health and substance abuse disorders: A review. Clin Psychol Rev 26: 162178.

16. Weitzel JA, Nochajski TH, Coffey SF, Farrell MG (2007) Mental health among suburban drug court participants. Am J Drug Alcohol Abuse 33: $475-481$.

17. McMillan GP, Timken DS, Lapidus J, C'de Baca J, Lapham SC, et al. (2008) Underdiagnosis of comorbid mental illness in repeat DUI offenders mandated to treatment. J Subst Abuse Treat 34: 320-325.

18. Peters RH, Hills HA (1997) Intervention strategies for offenders with co-occurring disorders: What works? National GAINS Center. Delmar NY.

19. Messina N, Burdon W, Hagopian G, Prendergast M (2004) One year return to custody rates among co-disordered offenders. Behav Sci Law 22: 503-508.

20. Sacks S, Cleland CN, Melnick G, Flynn PM, Knight K, et al. (2009) Violent offenses associated with co-occurring substance use and mental health problems: Evidence from CJDATS. Behav Sci Law 27: 5-69.

21. Cook LF, Weinman B (1988) Treatment alternatives to street crime. NIDA Res Monogr 86: 99-105.

22. Inciardi JA, McBride DC (1991) Treatment alternatives to street crime: History, experiences, and issues. In National Institute on Drug Abuse (Research monograph pp. 91-1749), Rockville MD U.S.

23. Anglin MD, Longshore D, Turner S, McBride D, Inciardi J, et al. (1996) Studies on the functioning and effectiveness of treatment alternatives to street crime (TASC) programs, final report. National Criminal Justice Reference Program NJC 169780.

24. Peters RH, LeVasseur ME, Chandler RK (2004) Correctional treatment for co-occurring disorders: Results of a national survey. Behav Sci Law 22: 563-584.

25. Peters RH, Bartoi, MG, Sherman PB (2008) Screening and assessment of co-occurring disorders in the justice system.CMHS National GAINS Center. Delmar, NY.

26. O'Brien CP, Charney DS, Lewis L, Cornish JW, Post RM, et al. (2004) Priority actions to improve health care of persons with co-occurring substance abuse and other mental disorders: A call to action. Biol Psychiatry 56: 703-713. 